\title{
Penerapan Algoritma CAST-128 pada Proses Enkripsi dan Dekripsi Teks
}

\author{
Yessi Sriani Barus ${ }^{1}$, Abdul Sani Sembiring ${ }^{2}$ \\ 1,2 STMIK Budi Darma Medan, Jl. Sisingamangaraja No. 338 Simpang Limun Medan \\ Email : yessibarus@gmail.com ${ }^{1}$, gurkiy@gmail.com ${ }^{2}$
}

\begin{abstract}
Abstrak- Penyandian yang pertama kali dibuat dengan menggunakan algoritma clasic. algoritma ini menumpukan keamanannya pada kerahasian algoritma yang digunakan. Namun algoritma ini tidak efisien saat digunakan untuk berkomunikasi dengan banyak orang karena algoritmanya masih sangat sederhana dan masih sangat mudah untuk dipecahkan, sehingga informasi atau data penting yang ingin dirahasiakan dengan mudah dapat diketehui orang lain atau orang yang tidak bertanggungjawab. CAST-128 adalah sebuah algoritma kriptografi yang dikatakan mirip dengan algoritma DES dimana menggunakan 16 putaran jaringan feistel sebagai salah satu kekuatannya. Dimana pada proses enkripsi dan dekripsi teks CAST-128 menggunakan panjang blok 64 bit dan panjang kunci sampai 128 bit. Sebagai informasi, algoritma CAST-128 ini disebut sebagai salah satu algoritma kriptografi yang kuat terhadap berbagai macam kriptanalisis, termasuk differential dan linear attack. Dengan adanya penerapan algoritma CAST-128 dalam proses enkripsi dan dekripsi teks akan lebih sulit untuk dipecahkan teks yang disandikan oleh orang-orang yang tidak mengetahui kuncinya sehingga dapat menciptakan keamanan yang lebih dari teks yang telah disandikan. Jadi ketika teks tersebut ingin dikirim atau dipindahkan ke flashdisk akan lebih terjaga kerahasiaannya.
\end{abstract}

Kata Kunci : Penerapan, Enkripsi, Dekripsi, teks dan Algoritma CAST-128.

Abstract- Encoding was first made using a classic algorithm. This algorithm builds its security on the confidentiality of the algorithm used. However, this algorithm is inefficient when used to communicate with many people because the algorithm is still very simple and still very easy to solve, so important information or data that you want to keep secret can be easily discovered by other people or people who are not responsible. CAST-128 is a cryptographic algorithm that is said to be similar to the DES algorithm which uses 16 rounds of feistel network as one of its strengths. Where in the process of encryption and decryption of text CAST-128 uses a 64-bit block length and key lengths of up to 128 bits. For information, the CAST-128 algorithm is referred to as one of the strong cryptographic algorithms against various types of cryptanalysis, including differential and linear attacks. With the application of the CAST-128 algorithm in the process of encrypting and decrypting text, it will be more difficult to decode text encoded by people who do not know the key so as to create more security than the encoded text. So when the text wants to be sent or transferred to the flashdisk will be more confidential.

Keywords: Implementation, Encryption, Decryption, text and CAST-128 Algorithm.

\section{PENDAHULUAN}

Kriptografi adalah suatu ilmu yang mempelajari bagaimana cara menjaga agar data atau pesan tetap aman saat dikirimkan, dari pengirim ke penerima tanpa mengalami gangguan dari pihak ketiga. Menurut Bruce Scheiner dalam bukunya "Applied Cryptography", kriptografi adalah ilmu pengetahuan dan seni menjaga message-message agar tetap aman (secure). Dalam kriptografi terdapat dua konsep utama yakni enkripsi dan dekripsi[1]. Enkripsi adalah proses mengacak data sehingga tidak dapat dibaca oleh pihak lain. Gambaran sederhana tentang enkripsi, misalnya mengganti huruf a dengan $\mathrm{n}, \mathrm{b}$ dengan $\mathrm{m}$. pembahasan enkripsi akan terfokus pada enkripsi password dan enkripsi komunikasi data. Dekripsi adalah upaya pengolahan data menjadi sesuatu yang dapat diutarakan secara jelas dan tepat dengan tujuan agar dapat dimengerti oleh orang yang tidak langsung mengalaminya sendiri[2].

Penyandian yang pertama kali dibuat dengan menggunakan algoritma clasic. algoritma ini menumpukan keamanannya pada kerahasian algoritma yang digunakan. Namun algoritma ini tidak efisien saat digunakan untuk berkomunikasi dengan banyak orang karena algoritmanya masih sangat sederhana dan masih sangat mudah untuk dipecahkan, sehingga informasi atau data penting yang ingin dirahasiakan dengan mudah dapat diketehui orang lain atau orang yang tidak bertanggungjawab [3].

CAST-128 adalah sebuah algoritma kriptografi yang menggunakan 16 putaran jaringan feistel sebagai salah satu kekuatannya. CAST-128 menggunakan panjang blok 64 bit dan panjang kunci sampai 128 bit. Sebagai informasi, algoritma CAST-128 ini disebut sebagai salah satu algoritma kriptografi yang kuat terhadap berbagai macam kriptanalisis, termasuk differential dan linear attack.

\subsection{Keamanan}

\section{LANDASAN TEORI}

Keamanan adalah keadaan bebas dari bahaya. Istilah ini bisa digunakan dengan hubungan kepada kejahatan, segala bentuk kecelakaan, dan lain-lain. Keamanan merupakan topik yang luas termasuk keamananan nasional terhadap serangan teroris, keamanan komputer terhadap hacker atau cracker, 
keamanan rumah terhadap maling dan penyelusup lainnya, keamanan finansial terhadap kehancuran ekonomi dan banyak situasi berhubungan lainnya[4].

\subsection{Kriptografi}

Kriptografi atau kriptologi merupakan keahlian dan ilmu dari cara-cara untuk komunikasi aman pada kehadirannya di pihak ketiga. Secara umum, kriptografi ialah mengenai mengkonstruksi dan menganalisis protokol komunikasi yang dapat memblokir lawan, berbagai aspek dalam keamanan informasi seperti data rahasia, integritas data, autentikasi, dan non-repudansi merupakan pusat dari kriptografi modern. Kriptografi modern terjadi karena terdapat titik temu antara disiplin ilmu matematika, ilmu komputer, dan teknik elektro. Aplikasi dari kriptografi termasuk ATM, password komputer, dan E-commerce. Kriptografi sebelum pada termodernisasi merupakan sinonim dari enkripisi, konversi dari kalimat-kalimat yang dapat dibaca menjadi kelihatan tidak masuk akal. Pembuat dari pesan enkripsi membagi teknik pemecahan sandi yang dibutuhkan untuk mengembalikan informasi asli jika hanya dengan penerima yang diinginkan, sehingga dapat mencegah orang yang tidak diinginkan melakukan hal yang sama. Sejak Perang Dunia I dan kedatangan komputer, metode yang digunakan untuk mengelola kriptologi telah meningkat secara komplek dan pengaplikasiannya telah tersebar luar[5].

Kriptografi modern sangat didasari pada teori matematis dan aplikasi komputer. Algoritma kriptografi didesain pada asumsi ketahanan komputasional, membuat algoritma ini sangat sulit dipecahkan oleh musuh. Secara teoritis, sangat sulit memecahkan sistem kriptografi, namun tidak layak melakukannya dengan cara-cara praktis. Skema ini disebut sangat aman secara komputasional, kemajuan teoritis dapat meningkatkan algoritma faktorisasi integer, dan meningkatkan teknologi komputasi yang membutuhkan solusi ini untuk diadaptasi terus-menerus. Terdapat skema keamanan informasi yang benar-benar tidak dapat ditembus bahkan dengan komputasi yang tak terbatas namun skema ini sangat sulit diimplementasikan.[3]

\subsection{Algoritma CAST-128}

CAST-128 didesain oleh Carlisle Adams dan Stafford Tavers dari Canada. CAST-128 termasuk kelas algoritma enkripsi yang menggunakan jaringan fiestel. Secara umum algoritma ini mirip dengan algoritma Data Encryption Standard (DES)[6]. Input dan keluaran dari algoritma CAST-128 adalah:

1. Input

a. Teks-asli p1..p64 (blok teks-asli sepanjang 64 bit)

b. Kunci $\mathrm{K}=\mathrm{kl}$...k128 (kunci sepanjang 128)

2. output

Teks-kode c1... c64 (blok kode sepanjang 64 bit).

Fungsi Enkripsi Dalam Algoritma CAST-128 yaitu:

1. Penjadwalan kunci yaitu menentukan 16 putaran upa-kunci (subkey) dari masukan pengguna.

2. Bagi blok menjadi dua bagian yaitu 64 bit teks-asli dibagi menjadi dua bagian yang sama, yaitu bagian kiri dan bagian kanan dengan panjang 32 bit.

3. 16 putaran jaringan fiestel.

4. Konkatenasi untuk membuat teks-kode yaitu tukarkan bagian kiri dengan bagian kanan blok diputaran terakhir. Setelah itu kedua bagian digabungkan menjadi satu dan menjadi teks-kode.

Langkah-langkah dekripsi identik dengan langkah-langkah algoritma enkripsi, hanya saja urutan jadwal kunci yang digunakan pada ke-16 putaran dibalik. Jadi kunci terakhir akan digunakan pada putaran pertama dan seterusnya sampai kunci petama digunakan pada putaran terakhir. (Dony Ariyus, hal 227:2008).

Model jaringan fiestel dengan menggunakan:

$$
\begin{gathered}
\mathrm{L}_{i}=\mathrm{R}_{i-1} \\
\mathrm{R}_{\mathrm{i}}=\mathrm{L}_{\mathrm{i}-1} \oplus \mathrm{f}\left(\mathrm{R}_{\mathrm{i}-1}, \mathrm{~K}_{\mathrm{i}}\right)
\end{gathered}
$$

Dalam hal ini i adalah bilangan bulat 1..r (jumlah putaran), $\mathrm{K}_{\mathrm{i}}$ adalah upa kunci pada putaran ke $\mathrm{i}$ sedangkan $\mathrm{F}$ adalah fungsi tranformasi.

Algoritma enkripsi CAST-128 didesain untuk mampu menerima berbagai macam panjang kunci 
yangn berbeda mulai dari 40 bit sampai dengan 128 bit [7], dimana perbedaan antara nilai tersebut harus dalam kelipatan delapan. Jadi panjang kunci yang valid adalah: 40, 48, 56, 64, 72, 80, 88, 96, 104, 112, 120, 128 bit. (Ade Gunawan, 2006).

\section{PEMBAHASAN}

CAST-128 adalah algoritma kriptografi kunci simetri yang mengenkripsi data per blok dengan panjang 64 bit, dan dengan panjang kunci yang bervariasi antara 40 sampai 128 dalam kelipatan delapan. CAST-128 menggunakan 16 putaran jaringan fiestel.

Langkah-langkah untuk mengenkripsi dengan menggunakan algoritma CAST-128 yang pertama, tentukan plainteks, lalu lakukan penjadwalan kunci yaitu menentukan 16 pasang upa-kunci (subkey) dari masukan pengguna, kedua bagi blok menjadi dua bagian yaitu 64 bit teks-asli dibagi menjadi dua bagian yang sama, yaitu bagian kiri (L) dan bagian kanan (R) dengan panjang 32 bit, lalu lakukan 16 putaran fiestel dengan menggunakan:

$$
\begin{gathered}
\mathrm{L}_{i}=\mathrm{R}_{i-1} \\
\mathrm{R}_{\mathrm{i}}=\mathrm{L}_{\mathrm{i}-1} \oplus \mathrm{f}\left(\mathrm{R}_{\mathrm{i}-1}, \mathrm{~K}_{\mathrm{i}}\right)
\end{gathered}
$$

Keterangan: i : bilangan bulat 1..r (jumlah putaran)

$\mathrm{K}_{\mathrm{i}}$ : upa kunci pada putaran ke $\mathrm{i}$

$\mathrm{F}$ : fungsi tranformasi (kombinasi)

Selanjutnya Konkatenasi untuk membuat teks-kode yaitu tukarkan bagian kiri dengan bagian kanan blok diputaran terakhir. Setelah itu kedua bagian digabungkan menjadi satu dan menjadi teks-kode.

Sedangkan langkah-langkah proses dekripsi identik dengan proses enkripsi, hanya saja proses penggunaan ke-16 kunci dalam perputarannya dibalik. Jadi kunci terakhir akan digunakan sebagai putaran pertama dan seterusnya sampai putaran pertama digunakan sebagai putaran terakhir.

Contoh proses enkripsi dan dekripsi menggunakan algoritma CAST-128:

Tabel 1. Plainteks terdiri dari 64 bit ( 8 karakter)

\begin{tabular}{|c|c|c|c|}
\hline No & Plainteks & Desimal & Biner \\
\hline 1. & Y & 089 & 01011001 \\
\hline 2. & E & 069 & 01000101 \\
\hline 3. & S & 083 & 01010011 \\
\hline 4. & S & 083 & 01010011 \\
\hline 5. & I & 073 & 01001001 \\
\hline 6. & A & 065 & 01000001 \\
\hline 7. & J & 074 & 01001010 \\
\hline 8. & A & 065 & 01000001 \\
\hline
\end{tabular}

Tabel 2. Kunci sebanyak 128 bit (16 karakter)

\begin{tabular}{|l|c|c|c|}
\hline No. & Plainteks & Desimal & Biner \\
\hline 1. & $\mathrm{~K}$ & 075 & 01001011 \\
\hline 2. & $\mathrm{E}$ & 069 & 01000101 \\
\hline 3. & $\mathrm{~L}$ & 076 & 01001100 \\
\hline 4. & $\mathrm{U}$ & 085 & 01010101 \\
\hline 5. & $\mathrm{~A}$ & 065 & 01000001 \\
\hline 7. & $\mathrm{G}$ & 071 & 01000111 \\
\hline 8. & $\mathrm{~A}$ & 065 & 01000001 \\
\hline No. & Plainteks & Desimal & Biner \\
\hline 9. & $\mathrm{~K}$ & 075 & 01001011 \\
\hline 10. & $\mathrm{U}$ & 085 & 01010101 \\
\hline 11. & $\mathrm{~K}$ & 075 & 01001011 \\
\hline 12. & $\mathrm{U}$ & 085 & 01010101 \\
\hline
\end{tabular}




\begin{tabular}{|l|l|l|l|}
\hline 13. & $\mathrm{~A}$ & 065 & 01000001 \\
\hline 14. & $\mathrm{~T}$ & 084 & 01010100 \\
\hline 15. & $\mathrm{~K}$ & 075 & 01001011 \\
\hline 16. & $\mathrm{U}$ & 085 & 01010101 \\
\hline
\end{tabular}

Adapun proses enkripsi yang dilakukan untuk menghasilkan cipherteks adalah:

1. Menentukan 16 pasang upa-kunci (subkey)

K1 : 0100101101001011

K2 : 0100010101010101

K3 : 0100110001001011

K4 : 0101010101010101

K5 : 0100000101000001

K6 : 0101001001000001

K7 : 0100011101010100

K8 : 0100000101010101

K9 : 0100101101001011

$\mathrm{K} 10: 0100101101001011$

K11 : 0100110001001011

K12 : 0101010101010101

K13: 0100000101000001

K14 : 0101001001000001

K15 : 0100011101010100

K16 : 0100000101010101

2. Bagi plainteks menjadi 2 bagian yang masing-massing menjadi 32 bit.

$\mathrm{R} 0=01011001010001010101001101010011$

L0 = 01001001010000010100101001000001

3. Proses putaran dengan jaringan fiestel

Putaran pertama:

$\mathrm{L} 1=01001000010000000100100101000000$

$\mathrm{R} 1=01011000010001000101001001010010$

Putaran ke-2:

$\mathrm{L} 2=01000111001111110100100000111111$

$\mathrm{R} 2=01001000010111000100111001001110$

Putaran ke-3:

L3 = 01000110001111100100011100111110

R3 = 01010000010001000001011000010110

Putaran ke-4:

L4 = 01000101001111010100011000111101

R4 = 01010110010000100100110001001100

Putaran ke-5:

L5 = 01000100001111000100010100111100

R5 = 01010101010000000000101000001010

Putaran ke-6:

L6 = 01000011001110110100010000111011

R6 = 01010001001110010000101100001011

Putaran ke-7:

L7 = 01000010001110100100001100111010

$\mathrm{R} 7=01011011011000000000001000000010$

Putaran ke-8:

L8 = 01000001001110010100001000111001

$\mathrm{R} 8=01000110001110100101110101011101$ 
Putaran ke-9:

L9 $=01000000001110000100000100111000$

R9 = 01010001011111010100100001001000

Putaran ke-10:

$\mathrm{L} 10=00111111001101110100000000110111$

$\mathrm{R} 10=00110000001010100010011100100111$

Putaran ke-11:

L11 = 00111110001101100011111100110110

$\mathrm{R} 11=01001001010000110011100000111000$

Putaran ke-12:

L12 = 00111101001101010011111000110101

$\mathrm{R} 12=0011000010111000011100100111001$

Putaran ke-13:

L13 = 00111100001101000011110100110100

$\mathrm{R} 13=01001101000000110100010001000100$

Putaran ke-14:

L14 = 00111011001100110100001000110011

$\mathrm{R} 14=00110100001111100011100000111000$

Putaran ke-15:

L15 = 00111010001100100100101100110010

R15 = 00110111001111010011111000111110

Putaran ke-16:

L16 $=010010010110010001101110101100100$

$\mathrm{R} 16=01001001011010000111011001110110$

4. Gabungkan L16 dan R16 dengan posisi R16 disisi kiri dan L16 pada bagian kanan untuk menghasilkan Cipherteks. Cipherteks yang dihasilkan adalah:

$\mathrm{C}=0100100101101000 \quad 011101100111011001001001011001000110110101100100$ (IhvvIdmd)

Untuk mengembalikannya ke bentuk semula dilakukan Proses dekripsi, dengan catatan putaran terahir pada proses enkripsi menjadi putaran pertama pada proses dekripsi. Adapun proses tersebut adalah sebagai berikut:

1. Putaran pertama:

$\mathrm{L} 1=01001001011010000111011001110110$

$\mathrm{R} 1=01001001011001000110110101100100$

2. Putaran ke-2:

$\mathrm{L} 2=00111011001100110100001000110011$

R2 = 00110100001111100011100000111000

3. Putaran ke-3:

L3 = 00111100001101000011110100110100

R3 = 01001101000000110100010001000100

4. Putaran ke-4:

L4 = 00111101001101010011111000111101

$\mathrm{R} 4=0011000010111000011100100111001$

5. Putaran ke-5:

L5 = 00111111001101100011111100110110

$\mathrm{R} 5=01001001010000110011100000111000$

6. Putaran ke-6:

L6 = 00111111001101110100000000110111

R6 = 01011011011000000000001000000010

7. Putaran ke-7: 
$\mathrm{L} 7=01000000001110000100000100111000$

$\mathrm{R} 7=01000110001110100101110101011101$

8. Putaran ke-8:

L8 = 01000001001110010100001000111001

$\mathrm{R} 8=01010001011111010100100001001000$

9. Putaran ke-9:

L9 = 01000010001110100100001100111010

R9 = 01001000010111000100111001001110

10. Putaran ke-10:

$\mathrm{L} 10=01000011001110110100010000111011$

$\mathrm{R} 10=01010000010001000001011000010110$

11. Putaran ke-11:

$\mathrm{L} 11=01000100001111000100010100111100$

$\mathrm{R} 11=01010101010000000000101000001010$

12. Putaran ke-12:

L12 = 01000101001111010100011000111101

$\mathrm{R} 12=01010001001110010000101100001011$

13. Putaran ke-13:

$\mathrm{L} 13=01000110001111100100011100111110$

$\mathrm{R} 13=01010000010001000001011000010110$

14. Putaran ke-14:

$\mathrm{L} 14=01000111001111110100100000111111$

$\mathrm{R} 14=01010110010000100100110001001100$

15. Putaran ke-15:

L15 = 01001000010000000100100101000000

R15 = 01011000010001000101001001010010

16. Putaran ke-16:

L16= 01001001010000010100101001000001

$\mathrm{R} 16=01011000010001000101001001010010$

4. Gabungkan L16 dan R16 dengan posisi R16 disisi kiri dan L16 pada bagian kanan untuk menghasilkan Cipherteks. Cipherteks yang dihasilkan adalah:

$\mathrm{C}=0101100001000100010100100101001001001001010000010100101001000001$ (YESSIAJA)

\section{HASIL}

Tampilan menu enkripsi dan dekripsi yang paling utama muncul pada saat menjalankan program yaitu seperti gambar di bawah, yang didalamnya terdapat beberapa pilihan yaitu pilih file untuk dienkripsi atau dekripsi, pilih lokasi penyimpanan, enkripsi, dekripsi dan exit atau keluar.

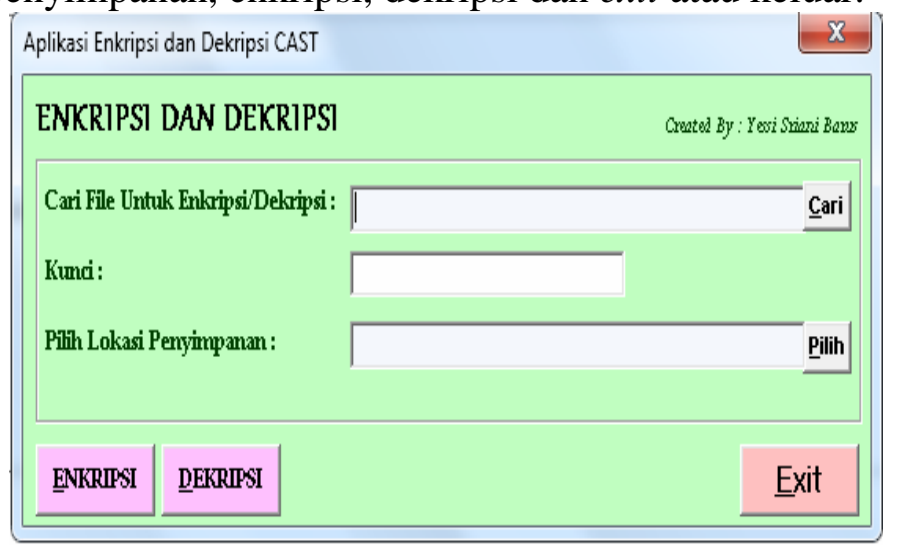

Gambar 1. Tampilan Menu Enkripsi dan Dekripsi 


\section{Tampilan Teks Untuk Enkripsi}

Persiapkan terlebih dahulu teks yang akan dienkripsi dalam notepad, lalu simpan dengan keterangan .txt. seperti gambar 2 di bawah

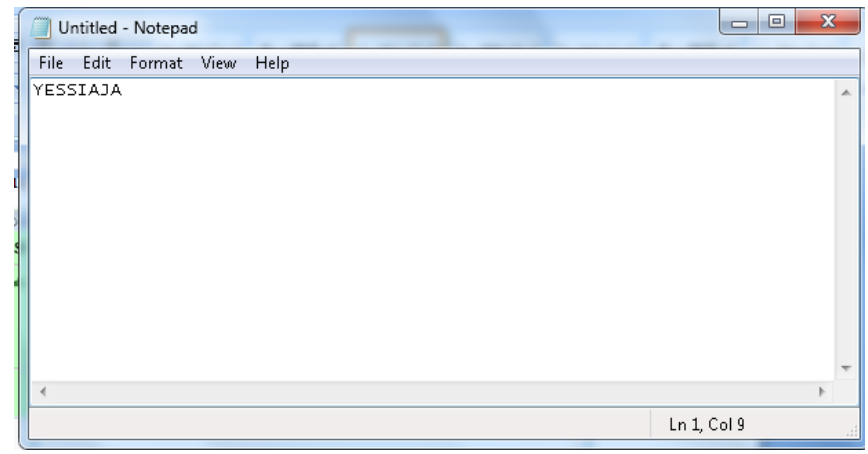

Gambar 2. Tampilan Teks Untuk Enkripsi

Dari menu enkripsi dan dekripsi ditampilkan menu pilih file untuk enkripsi/dekripsi. Setelah diklik, pilih teks yang telah disiapkan dalam notepad lalu ketikkan kunci KELUARGAKUKUATKU seperti gambar 3 di bawah

\begin{tabular}{|c|c|c|c|}
\hline \multicolumn{3}{|c|}{ Aplikasi Enkripsi dan Dekripsi CAST } & $x$ \\
\hline \multicolumn{3}{|c|}{ ENKRIPSI DAN DEKRIPSI } & Created By : Yøi S Sinni Bans \\
\hline \multicolumn{2}{|c|}{ Cari File Untuk Enkripsi/Dekpipsi: D:YYessiSrianiBarusiPlaintext.txt } & i: D:YYessiSrianiBarus'Plaintext.txt & Cari \\
\hline \multicolumn{2}{|l|}{ Kumci: } & KELUARGAKUKUATKU & \\
\hline \multicolumn{2}{|c|}{ Pith Lokasi Penyimpanan : } & D:YYessiSrianiBarusiCipertext & Pilitin \\
\hline ENKRIPSI & DEKRIPSI & & Exit \\
\hline
\end{tabular}

Gambar 3. Tampilan Input Kunci

Setelah kunci dimasukkan, pilih lokasi penyimpanan lalu klik tombol enkripsi maka akan tampil seperti gambar 4 dan 5 di bawah

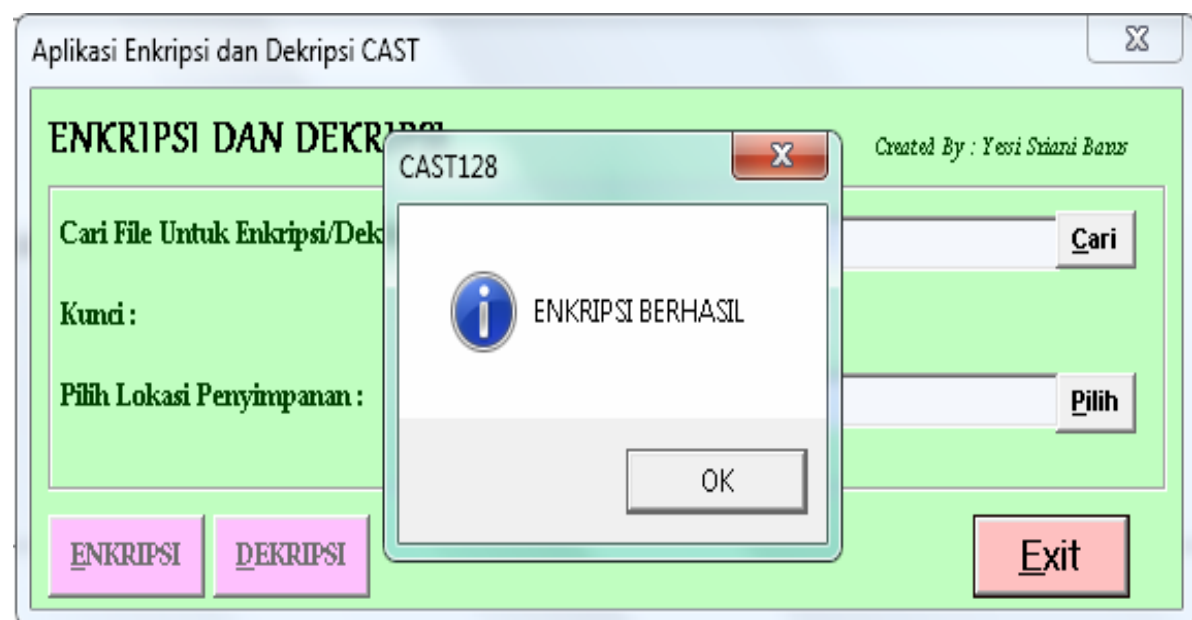

Gambar 4. Tampilan Enkripsi Berhasil 


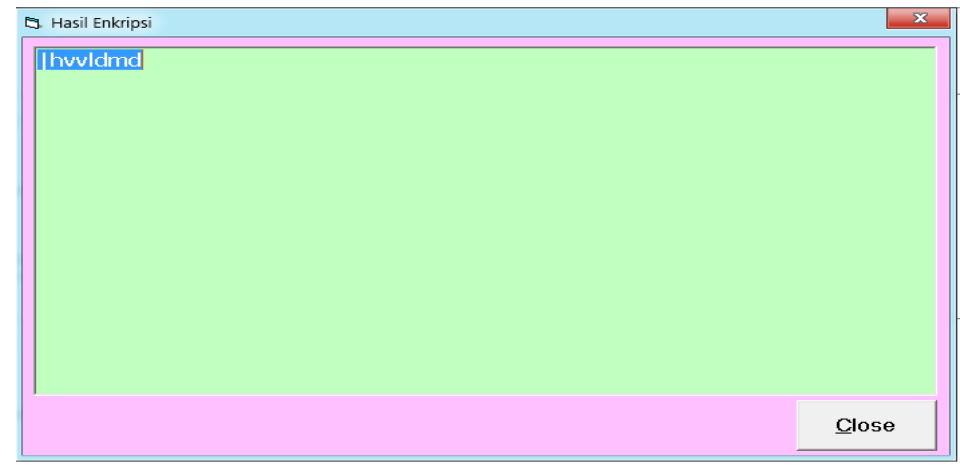

Gambar 5. Hasil Enkripsi

Hasil enkripsi yang tersimpan dalam notepad yaitu seperti gambar 6 di bawah

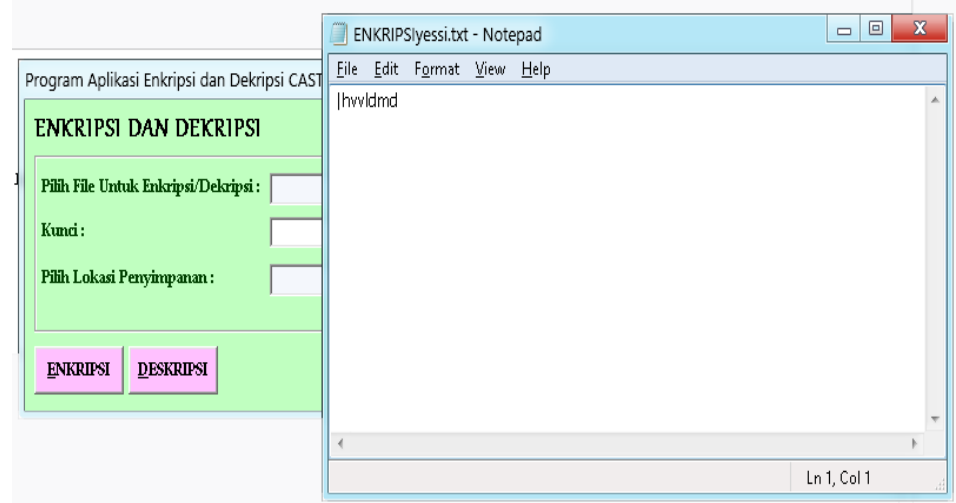

Gambar 6. Teks Yang Tersimpan

\section{Dekripsi Teks}

Setelah proses enkripsi maka akan menghasilkan cipherteks. Untuk mengembalikan cipherteks kebentuk semula maka dilakukan proses dekripsi. Proses dekripsi yang dilakukan yaitu mencari cipherteks yang telah tersimpan dalam notepad, input kunci, lalu pilih lokasi penyimpanan maka akan tampil seperti gambar 7 di bawah

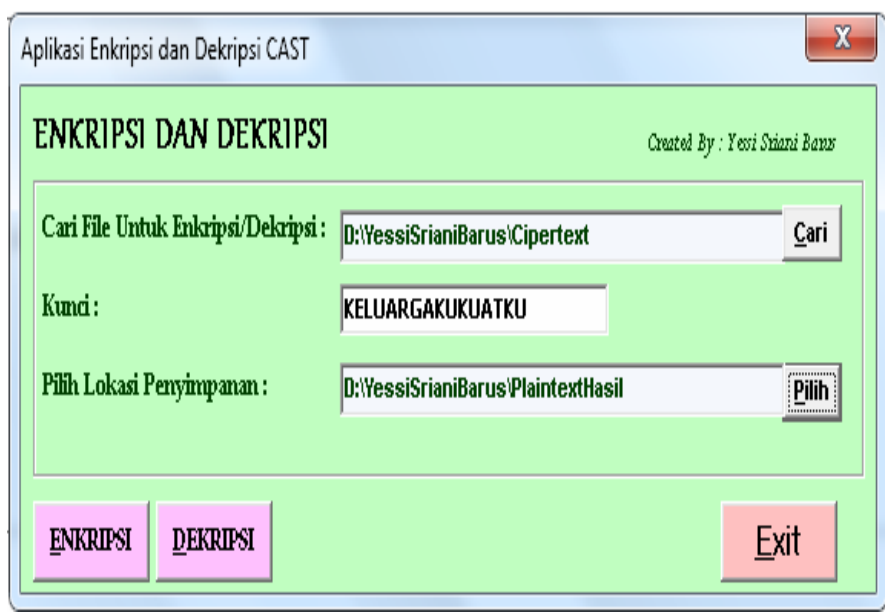

Gambar 7. Dekripsi

Setelah melakukan langkah penencarian cipherteks yang telah tersimpan dalam notepad, input kunci, lalu pilih lokasi penyimpanan dan pilih tombol DEKRIPSI maka hasilnya seperti gambar 8 di bawah 


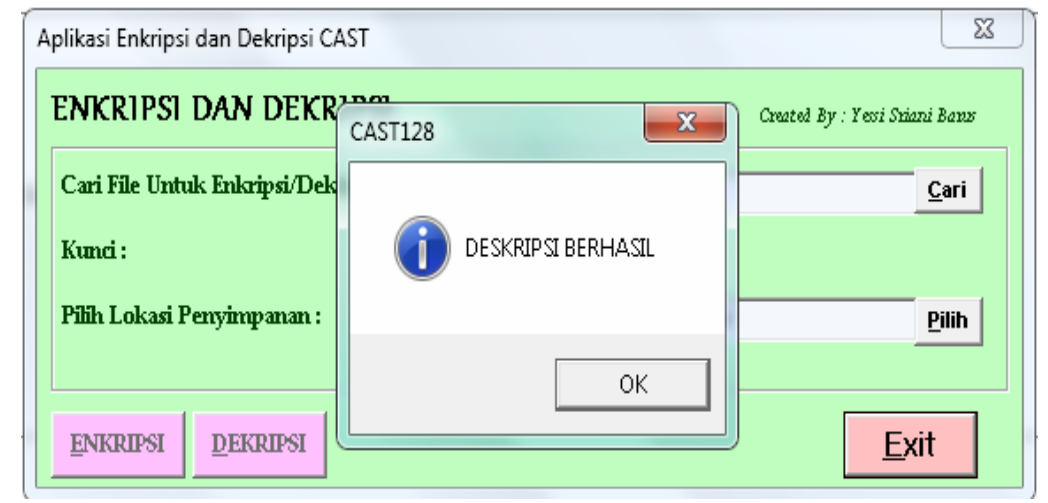

Gambar 8. Tampilan Dekripsi berhasil

Setelah dekripsi berhasil, lalu cari data yang telah disimpan maka hasilnya seperti gambar 9 di bawah

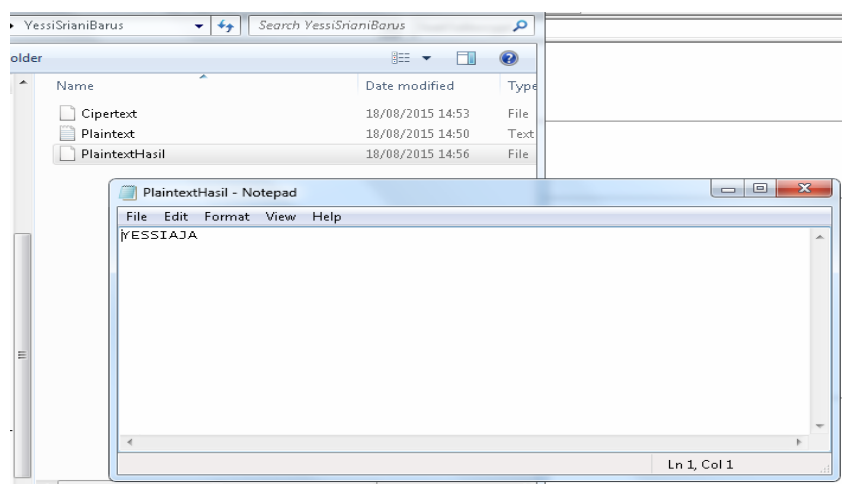

Gambar 9. Hasil Dekripsi

\section{KESIMPULAN}

Penerapan algoritma $C A S T$ - 128 memiliki 4 tahapan pada perubahan plainteks menjadi cipherteks dan sebaliknya, yaitu penjadwalan kunci atau penentuan 16 putaran upa kunci, penentuan blok, penggunaan 16 putaran jaringan fiestel, dan proses kontaktenasi.

\section{DAFTAR PUSTAKA}

[1] D. Ariyus, "Kriptografi keamanan data dan komunikasi," Yogyakarta Graha Ilmu, 2006.

[2] M. Qamal, "Kriptografi File Citra Menggunakan Algoritma Tea (Tiny Encryption Algorithm)," TECHSI - J. Penelit. Tek. Inform., 2014.

[3] R. Munir, "Kriptografi," Inform. Bandung, 2006.

[4] J. Simarmata et al., "Implementation of AES Algorithm for information security of web-based application," Int. J. Eng. Technol., vol. 7, no. 3.4 Special Issue 4, 2018.

[5] T. Limbong et al., "The implementation of computer based instruction model on Gost Algorithm Cryptography Learning," in IOP Conference Series: Materials Science and Engineering, 2018, vol. 420, no. 1, p. 12094.

[6] Z. Hercigonja, "Comparative Analysis of Cryptographic Algorithms," Int. J. Digit. Technol. Econ., vol. 1, no. 2, pp. 127-134, 2016.

[7] G. N. Krishnamurthy, "Encryption Quality Analysis and Security Evaluation of CAST-128 Algorithm and its Modified Version using Digital Images," Netw. Secur., vol. 1, no. 1, pp. 28-33, 2009. 